\title{
Sensitivity of the Fragility Curve on Type of Analysis Methods, Applied Ground Motions and Their Selection Techniques
}

\author{
Samreen Fatimah ${ }^{1} \cdot$ Jenna Wong $^{1}$ (D) \\ Received: 20 March 2020 / Accepted: 15 June 2021 / Published online: 26 June 2021 \\ (c) The Author(s) 2021
}

\begin{abstract}
Fragility curves are the primary way of assessing seismic risk for a building with numerous studies focused on deriving these fragility curves and how to account for the inherent uncertainty in the seismic assessment. This study focuses on a three-story steel moment frame structure and performs a fragility assessment of the building using a new approach called SPO2FRAG (Static Pushover to Fragility) that is based on pushover analysis. This new approach is further compared and contrasted against traditional nonlinear dynamic analysis approaches like Incremental Dynamic Analysis and Multiple Stripe Analysis. The sensitivity of the resulting fragility curves is studied against multiple parameters including uncertainties in ground motion, the type of analysis method used and the choice of curve fitting technique. All these factors influence the fragility curve behavior and this study assesses the impact of changing these parameters.
\end{abstract}

Keywords Fragility curves $\cdot$ Static pushover $\cdot$ IDA $\cdot$ MSA $\cdot$ SPO2FRAG

\section{Introduction}

Building collapse during an earthquake can lead to significant numbers of casualties and injuries. As a result, collapse prevention is a major design consideration emphasizing the need for seismic risk assessment of structures to estimate their potential collapse risk. The best way to evaluate collapse risk through probabilistic seismic risk assessment is using fragility curves which express a continuous relationship between a ground motion intensity measure (IM) and the probability that the structure will reach or exceed predefined damage states. The mathematical definition considered by researchers for fragility curves is a lognormal cumulative distribution function (CDF):

$P(C \mid I M=x)=\Phi\left(\frac{\ln (x / \theta)}{\beta}\right)$

where $\mathrm{P}(\mathrm{C} \mid \mathrm{IM}=\mathrm{x})$ is the probability that a ground motion with IM equal to $\mathrm{x}$ will cause the structure to collapse; $\Phi$ is the standard normal CDF; $\theta$ is the median of the fragility

Jenna Wong

jewong@sfsu.edu

1 San Francisco State University, 1600 Holloway Ave, San Francisco, CA 94132, USA function (the IM level with 50\% probability of collapse); and $\beta$ is the standard deviation of $\ln (\mathrm{IM})$ (sometimes referred to as the dispersion of IM).

Comprehensive fragility assessment of structural collapse requires a robust analytical model showing nonlinear behavior and an explicit consideration of the uncertainty in ground motion. Furthermore, this type of analysis method has inherent uncertainties due to the manner in which structural simulations are conducted (resulting in the key structural responses needed for assessment) and the curve fitting technique used to create the fragility curves. Therefore, all these parameters play a very important role in assessing the precision of the fragility curve.

The aim of this study is to examine the collapse failure probability of a steel moment frame derived using several approaches including: incremental dynamic analysis (IDA), multiple strip analysis (MSA), and a new method called SPO2FRAG. In addition, sensitivity to statistical curve fitting and use of far field, near field, and site-specific ground motions using conditional mean spectrum (CMS) are studied. To achieve this, a 2D three-story steel moment frame structure was modeled and studied using OpenSees (McKenna \& Fenves, 2000). 


\section{Background and Motivation}

\subsection{Background}

In order to do a comprehensive fragility assessment of a structure for seismic risk under different damage states, researchers have studied this subject from multiple approaches. They have compared different dynamic analysis methods as well as different suites of ground motions and their impact on structural response. The majority of the research has primarily focused on structural response with much less attention paid to the actual fragility curve fitting techniques and their accuracy.

The dominant dynamic analysis method traditionally used is the incremental dynamic analysis (IDA). IDA uses a single suite of ground motions rescaled to increasing intensity levels to obtain the structural response of the building (Cornell et al., 2002; Saruddin \& Nazri, 2015; Vamvatsikos \& Cornell, 2001). This structural response is then used to generate the fragility curve. As a result, this method is sensitive to ground motion input using various input motions to define multiple intensity levels. Since its inception, there have been efforts to increase its practical usage in industry such as progressive and approximate IDA (Azarbakht \& Dolsek, 2011; Han \& Chopra, 2006), reductions in the number of ground motions considered (Baharmast et al., 2015), optimization (Pujari et al., 2013), and expanse to various structural systems (Brunesi et al., 2015; Christovasilis et al., 2008). In terms of steel moment frames and near field motions, which is the focus of this study Taiyari et al. (2019) explored this topic through an extensive IDA analysis. However, in the study herein, the results of IDA are compared against other approaches to evaluate the fragility curve accuracy.

The ground motions themselves have evolved in characterization along with advancements in IDA. Probabilistic seismic hazard analysis (PSHA) is one of the most traditional characterizations that uses probability theory to relate the uncertainty of the earthquake source to the ground motion hazard (Cornell, 1968; Kramer, 1996; McGuire, 2004). But the selection of the ground motions is not randomly done. In itself, the discussion of ground motion selection has garnered numerous studies as well as guidelines throughout the past several decades (Bazzurro \& Cornell, 1999; McGuire, 1995; Petersen et al., 2008). From all of these studies, it is clear that the characteristics of the motions must be thoroughly considered in the selection process.

As a result, multiple stripes analysis (MSA) (Jalayer, 2003; Jalayer \& Cornell, 2008) was born out of this need to select PSHA motions consistent at each desired intensity level. MSA can use different suites of ground motion at each intensity level to obtain the structural response of the building. Baker (2013) considered the tradeoffs between using MSA versus IDA. He argued that IDA uses a single suite of ground motions rescaled to increasing intensity levels. Therefore, this approach requires a standardized set of motions which would not be representative of site-specific conditions at each intensity level. On the other hand, MSA used different suites of ground motions at each intensity level capturing different motion characteristics (such as magnitude, distance, and epsilon) at low and high intensity levels. Baker's findings showed that MSA is superior for measuring the collapse risk of a structure at a specific location provided site-specific information is available. As a result, this would fundamentally mean that the structural response obtained from a MSA would differ from the structural response obtained from an IDA and in turn produce further variance in the fragility curves. For both of these methods, the process is tedious due to the number of ground motions used and the analyses to be conducted. Baker (2015) further considered the efficiency of these structural analysis techniques by simulating synthetic data via a Monte Carlo approach. In doing so, MSA was more efficient in obtaining collapse fragility estimates than IDA for a given number of structural analyses. As such it has been widely accepted and used in a number of studies analyzing structural performance (Franchin et al., 2017; Ni et al., 2012; Scozzese et al., 2020).

In order to perform MSA, ground motions need to be selected. The traditional approach is the use of a Uniform Hazard Spectrum (UHS) where all the accelerations plotted have the same annual rate of exceedance. However, in 2011, Baker proposed the use of a Conditional Mean Spectrum (CMS) for this selection process. In contrast to UHS, CMS is a more realistic approach with probabilistically consistent hazard. CMS calculates the mean response spectrum by conditioning the target spectral acceleration value at the period of interest. Baker's findings showed that the structural response obtained from ground motions matching CMS is significantly smaller than analyses using UHS motions. These findings are crucial as this affects the accuracy of the fragility curve which in turn is vital in the "Seismic Risk Assessment" of a structure.

Thus far, only dynamic approaches have been considered for structural response assessment. However, there is another side to this discussion which includes static methods that can be further categorized into linear or nonlinear. Static pushover analysis (SPO) is one of the nonlinear static analysis (NLSA) approaches used recently in a new methodology for generating fragility curves, called static pushover to fragility (SPO2FRAG) (Baltzopoulos et al., 2017). This is an interactive and user-friendly software offering a practical solution for the analytical assessment of the seismic fragility of a building. The fundamental concept behind SPO2FRAG is the capability to efficiently predict the IDA results of a given Single Degree of Freedom system (SDOF) without actually having to run a time-consuming IDA. The SPO results 
are used to obtain an equivalent SDOF representation of the nonlinear structure and then the SPO2IDA algorithm produces the structural response. By using the SPO2IDA algorithm, the need for computationally demanding dynamic analysis is avoided. Additionally, the fragility functions may be estimated for multiple limit states using the intensity measure based analytical approach and the SPO2FRAG software also explicitly accounts for uncertainty in the fragility parameters. Since its development, SPO2FRAG has been used in a number of studies (Silva et al., 2019) especially for reinforced concrete buildings (Gentile et al., 2019; Milosevic et al., 2020; Ruggieri et al., 2020), however, there are far fewer studies related to steel structures (Pavel et al., 2018) for which this project helps to provide more insight into.

Although not considered in this study, there are other approaches being developed that are comparable to SPO2FRAG that require less analytical effort. One such approach was developed by Baharvand and Ranjbaran (2020) where a state-based-philosophy is used to create a new collapse fragility function called "SBP fragility function" that is nonprobabilistic in nature.

The study herein will expand further on the literature described above by evaluating both near field and far field motions along with performing MSA analysis with site specific ground motions. These motions will be used to compare traditional approaches of fragility development to the newer SPO2FRAG procedure to better understand the improvement in fragility accuracy.

\subsection{Motivation}

Traditional IDA has been the standard in generating fragility curves with current research focusing on developing improved alternative dynamic analysis methods. These efforts have especially focused on reducing the number of computations required while exploring the use of different suites of ground motions to better simulate site-specific conditions. This work in turn has led to discussions of the various tradeoffs in selecting ground motions and differences in the curve fitting techniques used.

With the advent of newer dynamic analysis approaches, there is a need to compare the results of the fragility curves produced by these methods to determine their effectiveness and accuracy. There is a lot to learn and understand by comparing these results providing new insight into the structural response and increasing our confidence in the accuracy of current fragility curves. The following sections take on this discussion by focusing on a new approach called SPO2FRAG and comparing it against traditional IDA and MSA approaches. The fragility curves obtained by all these approaches are compared to highlight curve sensitivities and the correlation or variance generated.

\section{Ground Motions}

For this study, a total of 20 records were used to cover a range of frequency content, duration, and amplitude. The ground motion database compiled for IDA analyses in this study constitutes a representative number of far field and near field ground motions from a variety of tectonic environments.

\subsection{Record Selection Criteria for IDA}

Ten near field and ten far field horizontal ground motion records were selected from the Pacific Earthquake Engineering Research (PEER) Center's Next Generation of Attenuation NGA West database (PEER Ground Motion Database: https://ngawest2.berkeley.edu/). The selected motions have a large variance in their max and $\min \mathrm{S}_{\mathrm{a}}$ to understand the effects of such a diverse ensemble of motions and investigate their inherent uncertainty. In addition, motions were scaled to allow for further investigation into their overall impact on structural response. Motions' amplitudes were scaled to a target acceleration value of $\mathrm{S}_{\mathrm{T}}\left(\mathrm{T}_{\mathrm{i}}, \zeta\right)$ which is the $5 \%$ damped spectral acceleration of the unscaled ground motion at $\mathrm{T}_{\mathrm{i}}$. The fundamental period of the structure $\left(\mathrm{T}_{\mathrm{i}}\right)$ chosen for this study is $0.94 \mathrm{~s}$ (see Sect. 5.2 for more details). Ground motion details are presented in Tables 1 and 2.

\subsection{Record Selection Criteria for MSA}

The steel moment frame building selected for study is an archetype structure found in literature (McCallen \& Larsen, 2003) with Las Vegas, Nevada identified for site-specific characterization. As such, this site was used in the PSHA. In this process, the UHS was obtained using hazard tools available from the United States Geological Survey (USGS) (furnished by the USGS Interactive Deaggregation Web Tool). These tools aided in determining the disaggregation based mean values for magnitude and distance. Tables 3 and 4 show the values obtained from USGS for the seismic hazard and CMS calculations.

The ground motions compiled for MSA analyses constitutes a set of 30 strong horizontal ground motion records (Direction 1 and Direction 2) and were selected from the PEER NGA West database. Ground motion details are presented below in Tables 5 and 6 . The ground motions were selected using a target CS mean and variance based on the ground motion selection algorithm by Jayaram et al. (2011). 
Table 1 Unscaled far field ground motion records for IDA analysis

\begin{tabular}{lllllll}
\hline No. & Earthquake & Magnitude & $\begin{array}{l}\text { Component H1 } \\
(\mathrm{Sa}, \mathrm{g})\end{array}$ & $\begin{array}{l}\text { Component H2 } \\
(\mathrm{Sa}, \mathrm{g})\end{array}$ & Ti (sec) & Year \\
\hline 1 & Loma Prieta & 6.9 & 0.526 & 0.395 & 0.94 & 1989 \\
2 & Northridge & 6.7 & 0.459 & 0.631 & 0.94 & 1994 \\
3 & Kobe, Japan & 6.9 & 0.521 & 0.383 & 0.94 & 1995 \\
4 & Imperial Valley & 6.5 & 0.448 & 0.49 & 0.94 & 1979 \\
5 & Chi-Chi, Taiwan & 7.6 & 0.342 & 0.561 & 0.94 & 1999 \\
6 & Manji Iran & 7.4 & 0.454 & 0.442 & 0.94 & 1990 \\
7 & Koecali, Turkey & 7.5 & 0.456 & 0.583 & 0.94 & 1999 \\
8 & Landers & 7.3 & 0.323 & 0.523 & 0.94 & 1992 \\
9 & Hector Mine & 7.1 & 0.290 & 0.350 & 0.94 & 1999 \\
10 & Chi-Chi, Taiwan & 7.6 & 0.651 & 1.179 & 0.94 & 1999 \\
\hline
\end{tabular}

Table 2 Unscaled near field ground motion records for IDA analysis

\begin{tabular}{lllllll}
\hline No. & Earthquake & Magnitude & $\begin{array}{l}\text { Component H1 } \\
(\mathrm{Sa}, \mathrm{g})\end{array}$ & $\begin{array}{l}\text { Component H2 } \\
(\mathrm{Sa}, \mathrm{g})\end{array}$ & Ti (sec) & Year \\
\hline 1 & Parkfield & 6.19 & 0.049 & 0.070 & 0.94 & 1966 \\
2 & Gazli & 6.8 & 0.842 & 0.471 & 0.94 & 1976 \\
3 & Tabas & 7.35 & 1.296 & 0.958 & 0.94 & 1978 \\
4 & Northridge & 6.69 & 0.789 & 0.604 & 0.94 & 1994 \\
5 & Chi-Chi & 7.62 & 0.917 & 0.944 & 0.94 & 1999 \\
6 & Imperial Valley & 6.53 & 0.205 & 0.294 & 0.94 & 2001 \\
7 & Nahanni & 6.76 & 0.407 & 0.653 & 0.94 & 1985 \\
8 & Kobe, Japan & 6.9 & 1.817 & 1.655 & 0.94 & 1995 \\
9 & San Fernando & 6.61 & 1.143 & 0.782 & 0.94 & 1971 \\
10 & Loma Prieta & 6.93 & 0.140 & 0.106 & 0.94 & 1989 \\
\hline
\end{tabular}

Table 3 Parameters for CMS Calculation (10\% Probability in 50 Years)

\begin{tabular}{ll}
\hline Parameter description & \\
\hline Location & Las Vegas, Nevada \\
Site Class & $\mathrm{D}(\mathrm{Vs}=260 \mathrm{~m} / \mathrm{s})$ \\
Return period of ground motion & 475 year \\
Conditioning period of structure, $\mathrm{T}_{\mathrm{i}}$ & $0.94 \mathrm{~s}$ \\
Mean representative magnitude, $\mathrm{M}$ & 6.76 \\
Mean representative site to source distance, $\mathrm{R}$ & $88.15 \mathrm{~km}$ \\
Epsilon & 0.8 \\
Ground motion prediction equation & Campbell and \\
& Bozorgonia \\
& $(2008)$ \\
\hline
\end{tabular}

\section{Methodology}

There are several approaches used to develop the collapse fragility functions. These approaches include: Intensity Measure (IM) for IDA; Engineering Design Parameters (EDP) for MSA; and SPO2FRAG.

The first-mode spectral acceleration denoted by $\mathrm{S}_{\mathrm{a}}\left(\mathrm{T}_{\mathrm{i}}\right)$ or simply $\mathrm{S}_{\mathrm{a}}$ hereon is used as the Intensity Measure (IM) for the analysis of collapse probability. Currently, the most
Table 4 Parameters for CMS Calculation (2\% Probability in 50 Years)

\begin{tabular}{ll}
\hline Parameter description & \\
\hline Location & Las Vegas, Nevada \\
Site Class & $\mathrm{D}(\mathrm{Vs}=260 \mathrm{~m} / \mathrm{s})$ \\
Return period of ground motion & 2475 year \\
Conditioning period of structure, $\mathrm{T}_{\mathrm{i}}$ & $0.94 \mathrm{~s}$ \\
Mean representative magnitude, $\mathrm{M}$ & 6.64 \\
Mean representative site to source distance, $\mathrm{R}$ & $52.02 \mathrm{~km}$ \\
Epsilon & 1.08 \\
Ground motion prediction equation & Campbell and \\
& Bozorgonia \\
& $(2008)$ \\
\hline
\end{tabular}

widely accepted IM for the collapse limit state is 5\% damped pseudo-spectral acceleration at the fundamental period of the structure $\left(\mathrm{T}_{\mathrm{i}}\right)$. Multiple authors have examined its suitability (Baker \& Cornell, 2006, Jalayer et al. 2012).

Structural response was obtained by performing the dynamic analysis of the building and expressed in terms of the EDPs. These EDPs were then compared with well calibrated thresholds for a collapse damage state or a performance level that was also expressed in terms of EDPs. 
Table 5 Site Specific ground motion records obtained for 2475-year return period ( $2 \%$ probability in 50 years)

\begin{tabular}{lrll}
\hline Number & $\begin{array}{l}\text { NGA Record } \\
\text { sequence No. }\end{array}$ & File Name Dir 1 & File Name Dir 2 \\
\hline 1 & 1697 & NORTH392/NBV250.at2 & NORTH392/NBV340.at2 \\
2 & 281 & TRINIDAD/BRDE000.at2 & TRINIDAD/BRDE270.at2 \\
3 & 1807 & HECTOR/0530a270.at2 & HECTOR/0530c360.at2 \\
4 & 1293 & CHICHI/HWA046-N.at2 & CHICHI/HWA046W.at2 \\
5 & 2982 & CHICHI05/CHY088N.at2 & CHICHI05/CHY088E.at2 \\
6 & 160 & IMPVALL/H-BCR140.at2 & IMPVALL/HBCR230.at2 \\
7 & 882 & LANDERS/NPS000.at2 & LANDERS/NPS090.at2 \\
8 & 1270 & CHICHI/HWA020-E.at2 & CHICHI/HWA020-N.at2 \\
9 & 2600 & CHICHI03/TCU042N.at2 & CHICHI03/TCU042E.at2 \\
10 & 188 & IMPVALL/H-PLS045.at2 & IMPVALL/H-PLS135.at2 \\
11 & 1153 & KOCAELI/BTS000.at2 & KOCAELI/BTS090.at2 \\
12 & 2366 & CHICHI02/TCU042N.at2 & CHICHI02/TCU042E.at2 \\
13 & 1350 & CHICHI/ILA067-E.at2 & CHICHI/ILA067-N.at2 \\
14 & 2002 & CABAJA/0523c090.at2 & CABAJA/0523a360.at2 \\
15 & 1082 & NORTHR/RO3000.at2 & NORTHR/RO3090.at2 \\
\hline
\end{tabular}

\begin{tabular}{llll}
\hline Number & $\begin{array}{l}\text { NGA Record } \\
\text { sequence No. }\end{array}$ & File Name Dir 1 & File Name Dir 2 \\
\hline 1 & 1117 & KOBE/TOT000.at2 & KOBE/TOT090.at2 \\
2 & 2957 & CHICHI05/CHY052N.at2 & CHICHI05/CHY052W.at2 \\
3 & 1258 & CHICHI/HWA005-N.at2 & CHICHI/HWA005-W.at2 \\
4 & 762 & LOMAP/FRE000.at2 & LOMAP/FRE090.at2 \\
5 & 1049 & NORTHR/SUN190.at2 & NORTHR/SUN280.at2 \\
6 & 1078 & NORTHR/5108-360.at2 & NORTHR/5108-090.at2 \\
7 & 1391 & CHICHI/KAU077-E.at2 & CHICHI/KAU077-N.at2 \\
8 & 730 & SPITAK/GUK000.at2 & SPITAK/GUK090.at2 \\
9 & 163 & IMPVALL/H-CAL225.at2 & IMPVALL/H-CAL315.at2 \\
10 & 68 & SFERN/PEL090.at2 & SFERN/PEL180.at2 \\
11 & 1576 & CHICHI/TTN024-E.at2 & CHICHI/TTN024-N.at2 \\
12 & 3202 & CHICHI05/TCU102N.at2 & CHICHI05/TCU102-E.at2 \\
13 & 1999 & GULFCA/0512a180.at2 & GULFCA/0512c270.at2 \\
14 & 1837 & HECTOR/0521a360.at2 & HECTOR/0521c090.at2 \\
15 & 2954 & CHICHI05/CHY046N.at2 & CHICHI05/CHY046-E.at2 \\
\hline
\end{tabular}

Table 6 Site Specific ground motion records obtained for 475 -year return period $(10 \%$ probability in 50 years)
In this study, the Maximum Interstory Drift (MIDR) was the selected EDP for the steel frame building. For example, Global Dynamic Instability is defined as a MIDR exceeding 10\%. However, Federal Emergency Management Agency (FEMA) 356 (FEMA 2000) and AISC 341 (AISC 2016) have threshold values for the Collapse Prevention Level set at $5.0 \%$. As a result, the following IDA analysis uses the traditional 10\% MIDR while the MSA and SPO2FRAG applies FEMA's 5\% MIDR. With this, this paper studies the correlation or lack thereof between the different methods.

For the IM based approach, a structure is subjected to a given ground motion and varying intensity levels till global dynamic instability is observed. The ground motion intensity at which dynamic instability is observed is called the IMc. Krawinkler et al. (2009) further defined IMc as the intensity at which a small increment causes a large increment in the lateral displacement. This approach was used in this study for the IDA analysis. IDA was performed by linearly increasing the IM level of ground motions till the IMc was obtained. This was repeated for a suite of ground motion records. These IMc values were statically evaluated and a probability distribution was fit to the data and this resulted in the generation of the fragility curve.

For the EDP based approach, our EDP for collapse is called the EDPc and is defined by the respective MIDR considered. Knowing this EDPc value, the dynamic analysis was 
run until the EDP met or exceeded this value confirming a collapse state. This approach was used in MSA and then a statistical procedure called Maximum Likelihood (Baker, 2015) was used to generate the fragility function.

For SPO2FRAG, the method starts with the generation of a SPO curve of the multi-degree of freedom (MDOF) system in OpenSees. This curve is then supplied as input to SPO2FRAG to generate a SDOF backbone curve. This is achieved by taking the global stiffness of the building in the lateral direction as defined by the SPO. It is important to note that the pushover curve was idealized as a quadrilinear fit with piece-wise linear segments representing the elastic, hardening, softening, and residual strength. The MDOF dynamic characteristics are preserved by including the mass, height, and number of stories to determine the modal characteristics. SPO2FRAG then simulated nonlinear dynamic analysis via the Static Pushover to IDA (SPO2IDA) algorithm. In this step, $16 \%, 50 \%$ and $84 \%$ fractile IDA curves of an equivalent SDOF system were estimated using this algorithm. Finally, the EDPs are defined in two ways: (a) Roof story drift angle (or ratio) $\theta_{\mathrm{R}}$, and (b) Maximum interstory drift angle (or ratio) $\theta_{\text {ID }}$. SPO2FRAG also offers the feature to add additional variability to different structural and ground motion parameters. However, in this study, these variables were not considered. Fragility curves are generated using two options: (1) Use half-distance between 16 and $84 \%$ fractile IDA curve and (2) half-distance between median and $16 \%$ fractile IDA curve. This study used option 1 .

\section{Model Description}

\subsection{Frame Structure Description}

A three-story steel moment frame structure from literature (McCallen \& Larsen, 2003) was considered for this study. This archetype structure shown in Fig. 1 was designed and based on Uniform Building Code (UBC) for zone 3 and is comparable to the SAC steel project designs. (The SAC project was funded by FEMA to solve the problem of brittle behavior of welded steel frame structures that surfaced in the January 17, 1994 Northridge California.) Fig. 1 shows the geometric configuration of the frame modeled.

OpenSees was used to model this frame with all base nodes defined with fixed restraints. For each floor, there is an equal distribution of the floor mass with the mass concentrated at the beam-column joints of the frame. To have rigid diaphragm behavior, all nodes are horizontally constrained for displacement. The beam and column members are modeled using force-based elements with fiber sections. Five integration points are used to account for yielding and plastic deformation along the element length under the increasing loads. The storey mass for floor $1=1.803 \mathrm{kips}$, floor $2=1.688 \mathrm{kips}$ and floor $3=1.227 \mathrm{kips}$. Gravity loads of 0.1344 kips are assigned to the beam-column joint nodes and gravity loads tributary to the frame members are assigned to the frame nodes. To develop a model capable of producing a credible prediction of the nonlinear behavior in the structure, a steel material $(\mathrm{E}=29,000 \mathrm{ksi}$ and $\mathrm{Fy}=50 \mathrm{ksi})$ was used that adopted the Menegotto-Pinto material model. The structure was considered to have 5\% damping.

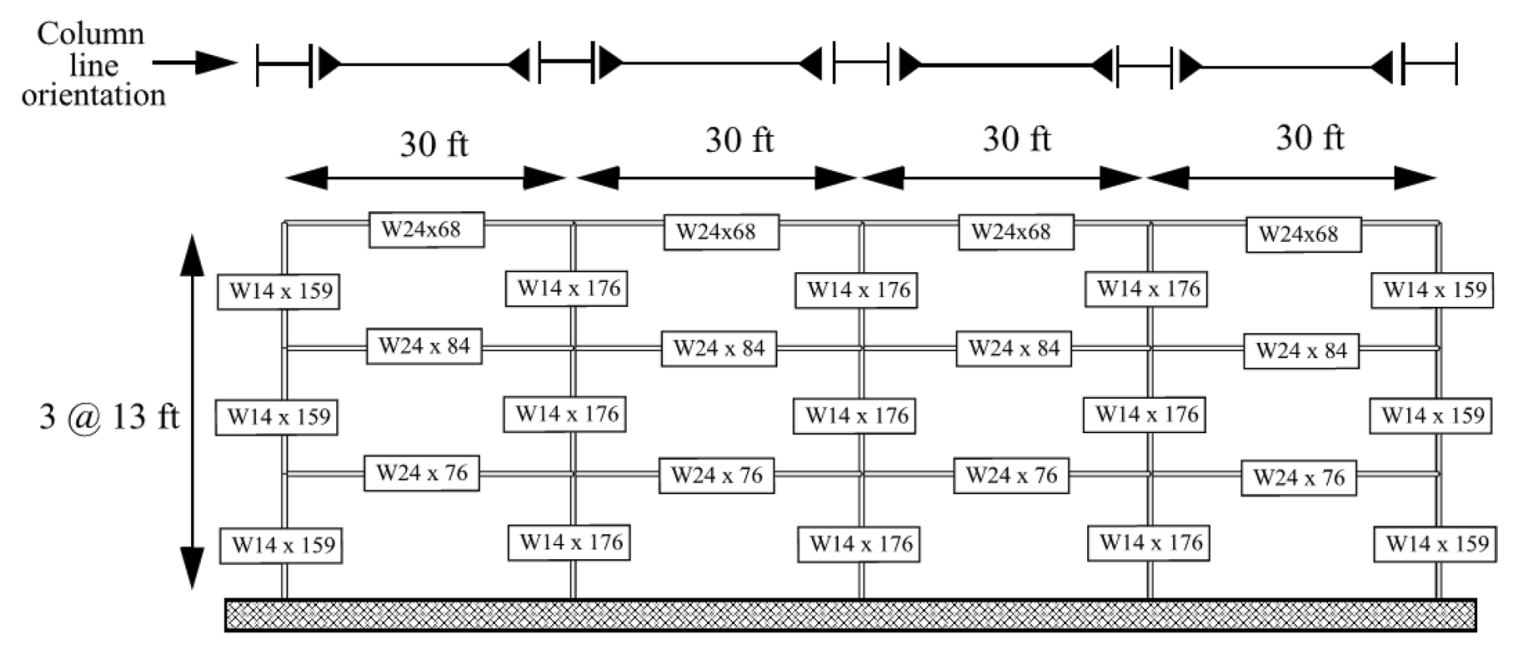

Total tributary weight to frame $=1.901 \times 10^{6} \mathrm{lb}$

Fig. 1 Structural Frame (McCallen \& Larsen, 2003) 
P-Delta effects are considered by modelling a leaning column one bay width away from the frame and connecting it back to the frame with a truss element. These leaning columns are pinned at the base. An elastic beam column element $\left(\mathrm{A}_{\text {leaning column }}=1,000.0 \mathrm{in}^{2}\right.$ and $\left.\mathrm{I}_{\text {leaning column }}=100,000.0 \mathrm{in}^{4}\right)$ is used to model the leaning columns and to transfer P-Delta effects. A truss element $\left(A_{\text {truss }}=1000.0 \mathrm{in}^{2}\right)$ is used to connect the frame and the leaning columns.

\subsection{Model Verification}

To check the dynamic characteristics of the structure, an eigenvalue analysis was used to verify the model against existing data available in literature. The structure has a fundamental mode $\left(\mathrm{T}_{\mathrm{i}}\right)$ of $0.94 \mathrm{~s}$. To check nonlinearity in the model, a pushover analysis was performed. The initial OpenSees model had P-Delta geometric nonlinearity and the pushover curve generated would show typical nonlinear behavior but it was not showing any strength deterioration (see Fig. 2 below). This atypical behavior was explored leading to the inclusion of the P-Delta gravity column. P-Delta effects are considered by modelling a leaning column one bay width away from the frame and connecting it back to the frame with a truss element. These leaning columns are pinned at the base. An elastic beam column element (Aleaning column $=1,000.0$ in 2 and Ileaning column $=100,000.0$ in 4 ) is used to model the leaning columns and to transfer P-Delta effects. A truss element (Atruss $=1000.0$ in2) is used to connect the frame and the leaning columns.

The analysis was rerun with these new parameters and the resulting pushover curve had nonlinearity and significant strength deterioration (See Fig. 3).

\section{Results}

The following sections present the fragility curves produced using the SPO2FRAG, MSA, and IDA methods. These curves are then compared in Sect. 6.4.

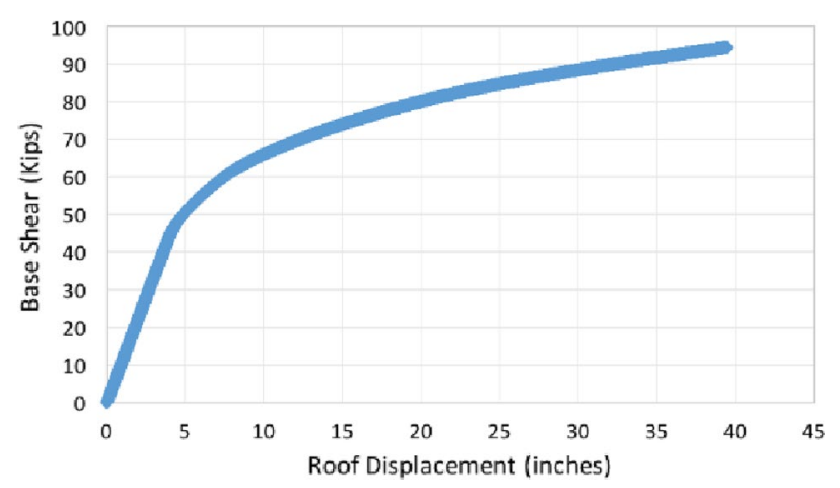

Fig. 2 Initial Pushover Curve

\subsection{SPO2FRAG (Static Pushover to Fragility Analysis)}

SPO2FRAG estimates the structure specific seismic fragility curve by simulating the results of IDA via the SPO2IDA algorithm and an equivalent SDOF approximation of the structure. Therefore, the SPO2FRAG analysis is broken down into two stages: (1) SPO to IDA tools and (2) Fragility Curve tools.

\subsubsection{Stage I: SPO to IDA Tool}

In this stage, the fragility IDA curves are generated. For the equivalent SDOF system, the backbone curve is defined by the pushover curve shown in Fig. 3 and inputted into the SPO2FRAG software. A quadrilinear fitting is chosen to create an idealized piecewise representation of the backbone curve as shown in Fig. 4. To maintain the dynamic characteristics of the MDOF system, the information related to the

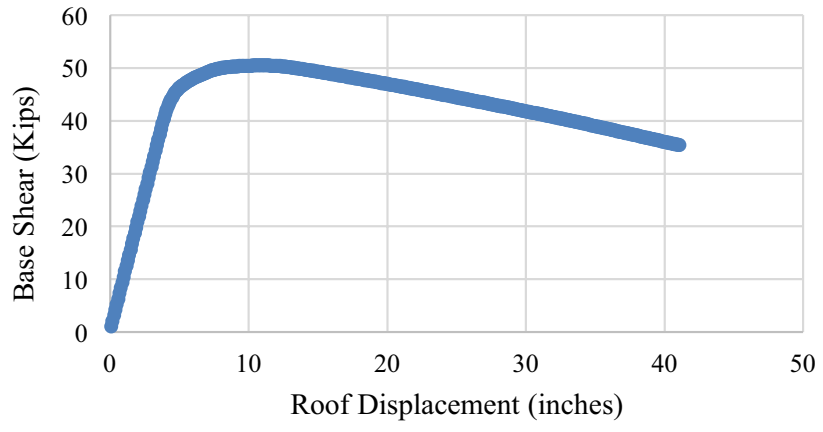

Fig. 3 Pushover Curve with P-Delta Gravity Column

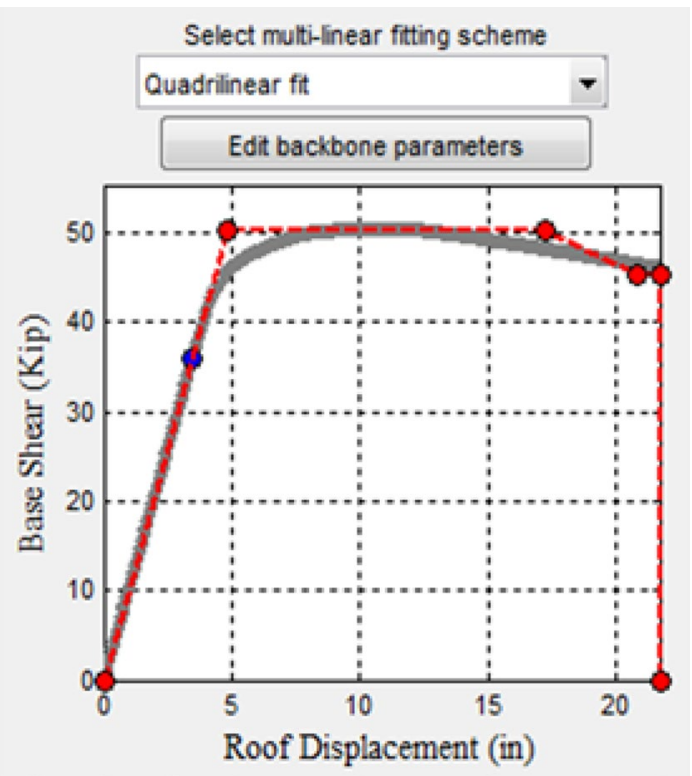

Fig. 4 Idealized Backbone Curve in SPO2FRAG 
mass, height and number of stories is inputted to create an equivalent SDOF system. The equivalent SDOF system has mass $\mathrm{m}^{*}$ which is given as a function of the structure's floor masses via $m^{*}=\sum_{i=1}^{n} m_{i} \cdot \emptyset_{i}$. The reaction force $\left(F^{*}\right)$ and displacement $\left(\delta^{*}\right)$ are calculated by taking the structure's base shear $\left(F_{b}\right)$. and roof displacement $\left(\delta^{\text {roof }}\right)$ and dividing these values by the modal participation factor $F\left(F^{*}=F_{b} / F\right.$ and $\delta^{*}=\delta^{\text {roof }} / F$ ). The modal participation factor can be calculated as $\mathrm{F}=m^{*} / \sum_{i=1}^{n} m_{i} \cdot \emptyset_{i}^{2}$ (Fajfar, 2000). (Note: Although $\Gamma$ is typically used to symbolize the participation factor, the SPO2FRAG software uses $F$. As such, to maintain consistency with the software, $F$ will be used hereon.) The period of vibration of the equivalent SDOF system, $T^{*}$, is calculated as: $T^{*}=2 \pi \cdot \sqrt{\frac{m^{*} \cdot \delta_{y}^{*}}{F_{y}^{*}}}$ (Baltzopoulos et al., 2017) and the definition of $F_{y}^{*}$ and $\delta_{y}^{*}$ depends on the piecewise linear approximation adopted for the SPO curve in Fig. 4.

The software then generates the Fractile IDA curves of the equivalent SDOF system as shown in Fig. 5. In this step, $16 \%, 50 \%$ and $84 \%$ Fractile IDA curves are estimated using the software's SPO2IDA algorithm using the piecewiselinear backbone curve.

\subsubsection{Stage II: Fragility Curve Tool}

In this step, the final form of the fragility curve is achieved. Based on FEMA 356 and AISC 41, the following limit states were used to define the EDP at difference performance levels:

(a) Full Operational Level: 0.4\%

(b) Immediate Occupancy Level: $0.7 \%$

(c) Life Safety Level: $2.5 \%$

(d) Collapse Prevention Level: 5.0\%

(e) Side-Sway Collapse Level: $6.0 \%$

As the collapse performance state was the focal point of the study, the fragility curve was then generated from SPO2FRAG for this performance level as shown in Fig. 6.

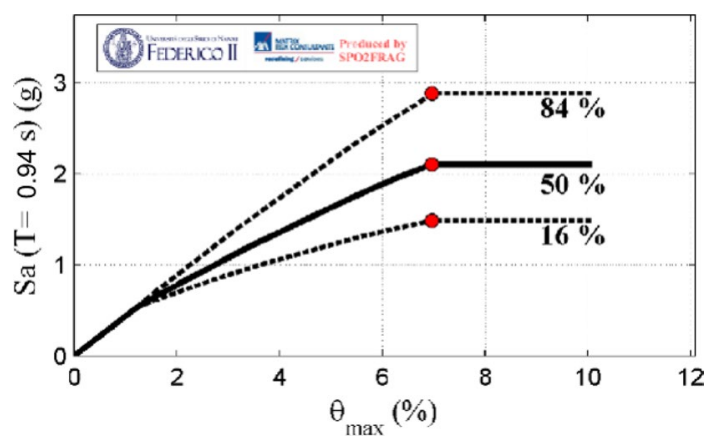

Fig. 5 Fractile IDA Curves Generated in SPO2FRAG

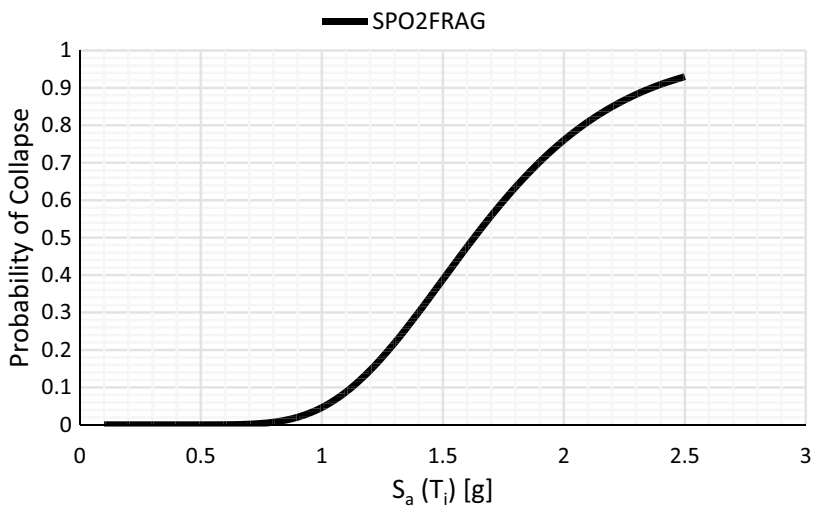

Fig. 6 SPO2FRAG Fragility Curve

\subsection{Multiple Stripe Analysis (MSA)}

This section generates the fragility curve using MSA.

For MSA, a CMS was developed as shown in Fig. 7 using a MATLAB script developed by Baker and Lee (2018). The parameters provided in Tables 3 and 4 are used as an input to this MATLAB code. For the study's steel frame, the CMS is conditioned at the structure's fundamental period (i.e. $0.94 \mathrm{~s}$ ) and is constructed at varying IM levels. Ground motions were selected at hazard levels of 475-year and 2475year return periods. A set of 30 records that best represent the given CMS were selected. Figure 7 shows the response spectra for the 30 ground motions selected.

The results from the MSA analysis identify the number of ground motions at each IM level that cause collapse. This number is then divided by the total number of ground motions used in the analysis to determine the collapse probability. The "Maximum Likelihood" procedure (Baker, 2015) was used to construct the collapse fragility curve at different hazard levels. The analyses were performed up to IM amplitudes where the ground motion caused collapse. Figure 8 presents the raw data generated. Using the cumulative distribution function (CDF), these probabilities are plotted at discrete hazard levels creating the fragility curve following a fragility fitting method proposed by Baker (2015), hereon "Baker, 2015". Figure 9 presents the MSA fragility curve.

\subsection{Incremental Dynamic Analysis (IDA)}

This section generates the fragility curve using IDA.

For IDA, results were obtained for a suite of 20 ground motion records (10 far field and 10 near field). Figures 10 and 12 illustrate the IDA curves. Each IDA curve traces the MIDR for a given ground motion record as a function of $S_{a}\left(T_{i}\right)$ as the record's amplitude is linearly scaled up to a level where it causes global dynamic instability i.e., 

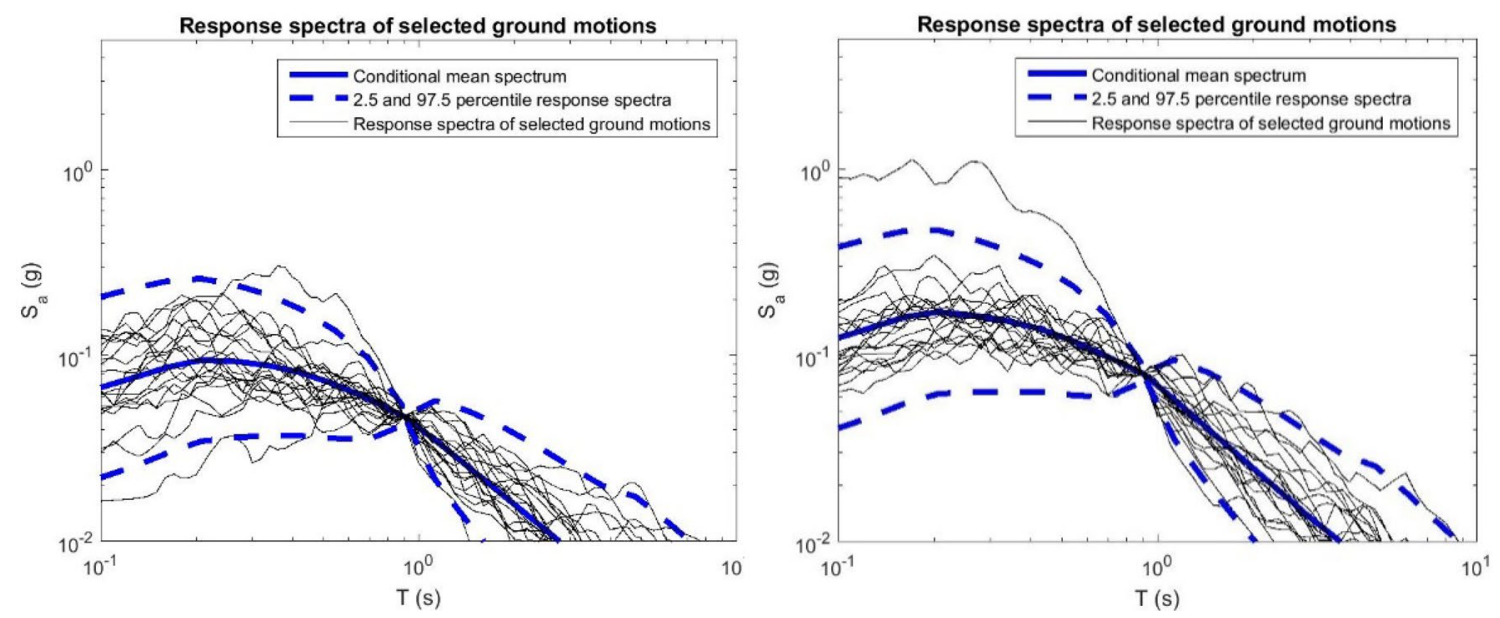

Fig. 7 Response Spectra of GMs selected for 2475 year (2\% probability in 50 years) (left) and 475 year (10\% probability in 50 years) (right) return period

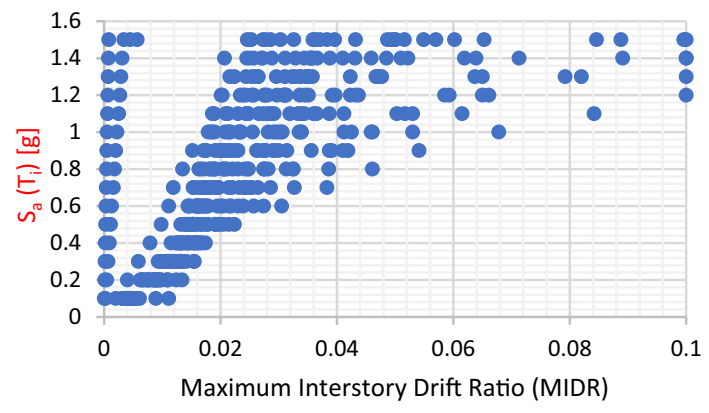

Fig. 8 MSA Raw Data

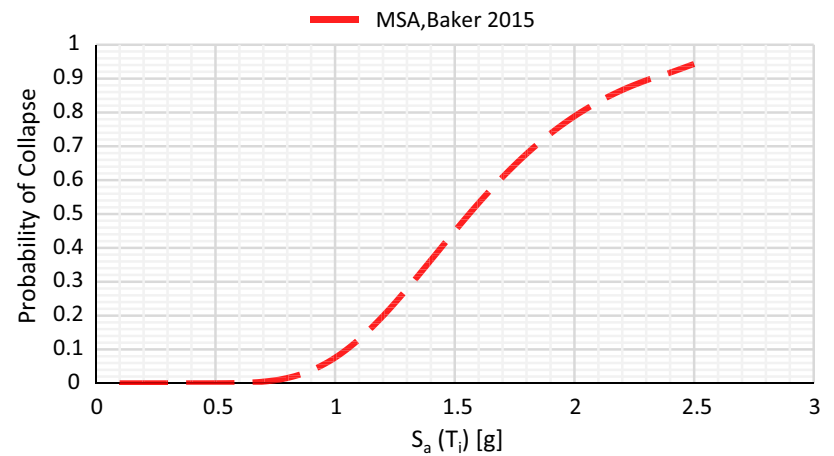

Fig. 9 MSA Fragility Curve

maximum inter-story drift exceeding $10 \%$ which is defined as the collapse criterion in this study.

These IDA curves exhibit a range of responses with some showing gradual progress to collapse while others present more oscillatory responses as it approaches this damage state. Notably, for at least 3 ground motions, the structure was not capable of achieving a MIDR of $10 \%$.
This data indicates that the characteristics of the IDA curve particularly depends upon the attributes of the underlying ground motion. The reasoning for this inability to reach the specified MIDR is beyond the scope of this study; however, other researchers such as Vielma et al. (2020) has initiated research focused on how the numerical model, structure type and the set of ground motions influence IDA results. Additionally, in consideration of near field motions, there are examples of near field structures with low structural damage even in extreme magnitude events such as Chi-Chi (Pitarka et al., 2009; Somerville \& Pitarka, 2006). In this case, it was actually structures located further away from the fault line that experienced more significant damage. The underlying reason was associated to the difference in ground motion characteristics between earthquakes with shallow slip (very low high frequency seismic energy) and earthquakes on buried faults or with deep slip (high energy at high frequencies). As such, these ground motion characteristics were beyond the considerations made for record selections.

Figure 10 shows the IDA plot for the Near field records and the corresponding Near Field Fragility curve is show in Fig. 11. The Far Field IDA plot is shown in Fig. 12 and the corresponding Far Field Fragility curve is shown in Fig. 13.

\subsection{Fragility Curve Comparison}

Through the various methods described above, a comparison of the results is shown in Fig. 14 and Table 7.

First, let us compare the MSA curve against the SPO2FRAG result. The two curves are in close agreement with identical results for $S_{a}\left(T_{i}\right)<0.7 \mathrm{~g}$. Above this spectral acceleration, the results diverge with the maximum difference occurring at $\mathrm{S}_{\mathrm{a}}\left(\mathrm{T}_{\mathrm{i}}\right)=1.2 \mathrm{~g}$. At this point, MSA presents a $20 \%$ collapse probability while SPO2FRAG presents a $14 \%$ 
Fig. 10 IDA plot for Near field GM records

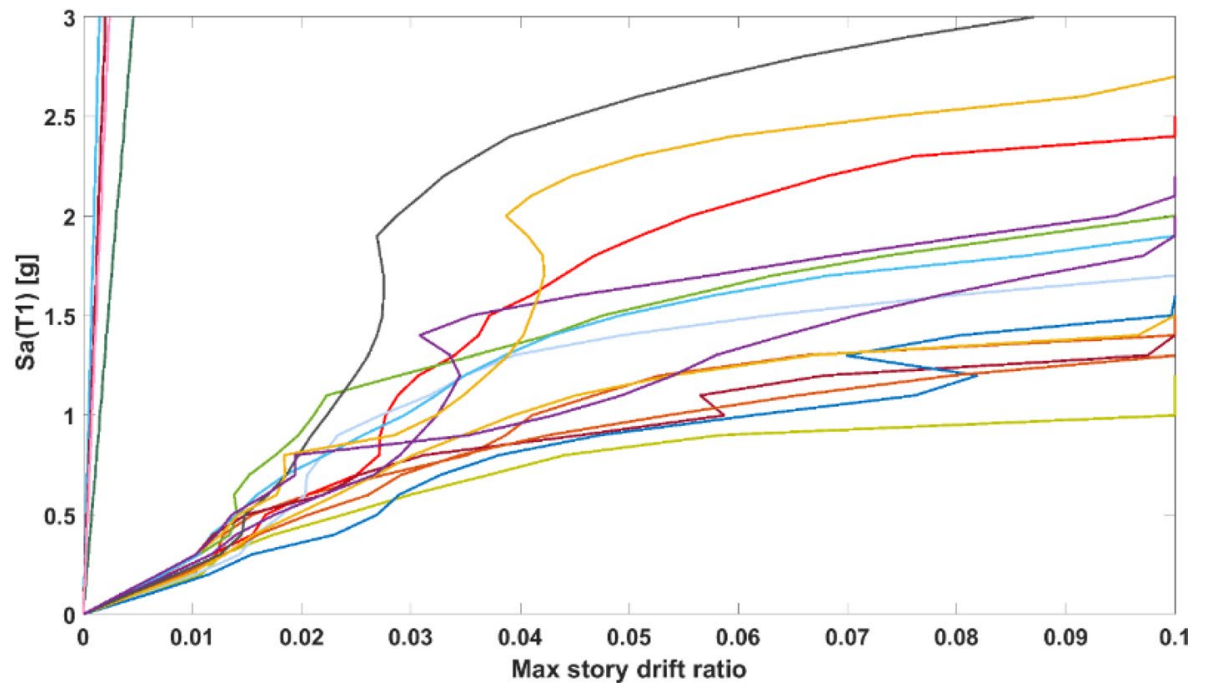

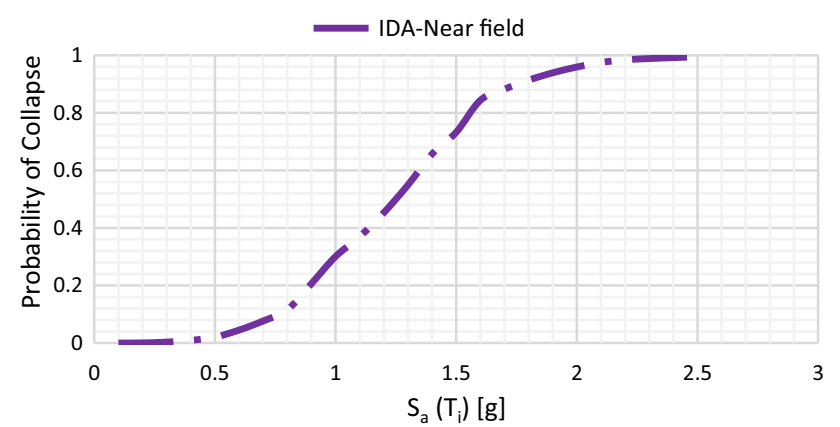

Fig. 11 IDA Fragility Curve for Near Field Records

probability. Differences between the two curves are present up until a $\mathrm{S}_{\mathrm{a}}\left(\mathrm{T}_{\mathrm{i}}\right)=2.4 \mathrm{~g}$. The MSA fragility curve is marginally conservative compared to SPO2FRAG.
Next, both IDA curves begin to diverge from the MSA and SPO2FRAG results at $\mathrm{S}_{\mathrm{a}}\left(\mathrm{T}_{\mathrm{i}}\right)=0.4 \mathrm{~g}$. By $\mathrm{S}_{\mathrm{a}}\left(\mathrm{T}_{\mathrm{i}}\right)=1 \mathrm{~g}$, the curves have significant differences (IDA curves are above $19 \%$ while MSA/SPO2FRAG are under 7\%) in their collapse probability. This trend continues up to $\mathrm{S}_{\mathrm{a}}\left(\mathrm{T}_{\mathrm{i}}\right)=1.6 \mathrm{~g}$ where all 4 curves reach their maximum divergence. At this point, the IDA near field yields a $84 \%$ probability of collapse while the IDA far field scenario yields a $65 \%$ probability. These probabilities are both much higher compared to the $53 \%$ and $47 \%$ probabilities produced by the MSA and SPO2FRAG methods, respectively. The data shows that beyond $\mathrm{S}_{\mathrm{a}}\left(\mathrm{T}_{\mathrm{i}}\right)=1.6 \mathrm{~g}$, all four fragility curves begin to converge and by $\mathrm{S}_{\mathrm{a}}\left(\mathrm{T}_{\mathrm{i}}\right)=2.5 \mathrm{~g}$, the spread between the max and min collapse probability is only $5 \%$ (i.e., near field $99 \%$ vs. SPO2FRAG 93\%).

Evidently the collapse fragility of a structure varies significantly depending on the choice of ground motion
Fig. 12 IDA plot for Far field GM records

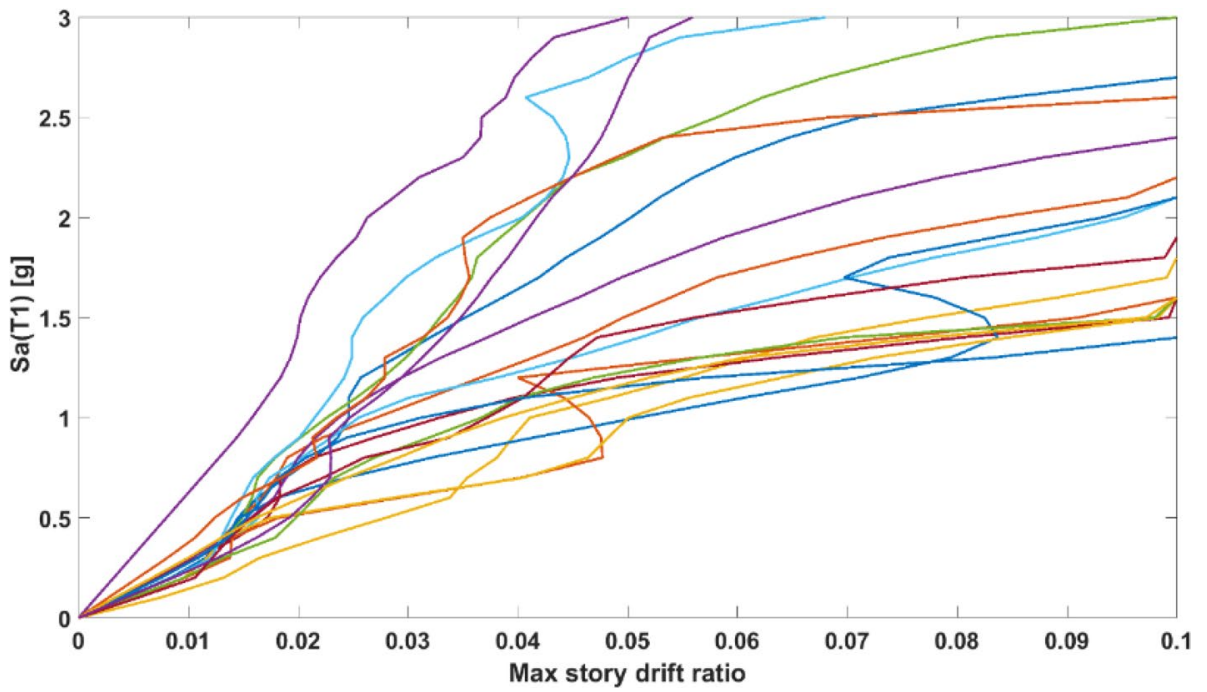




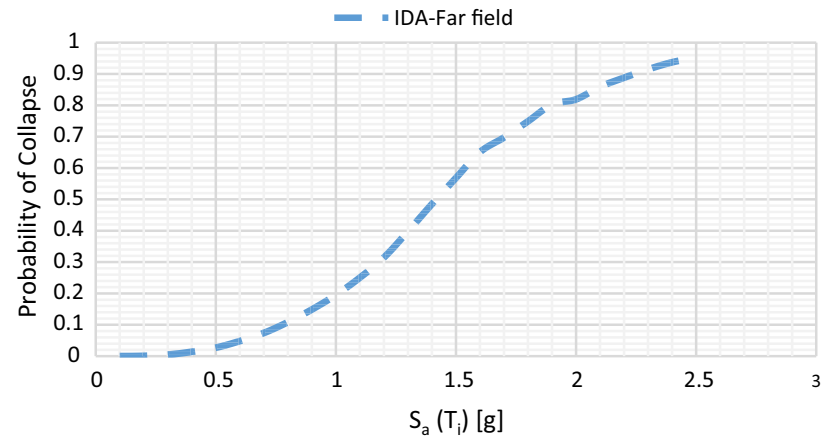

Fig. 13 IDA Fragility Curve for Far field records

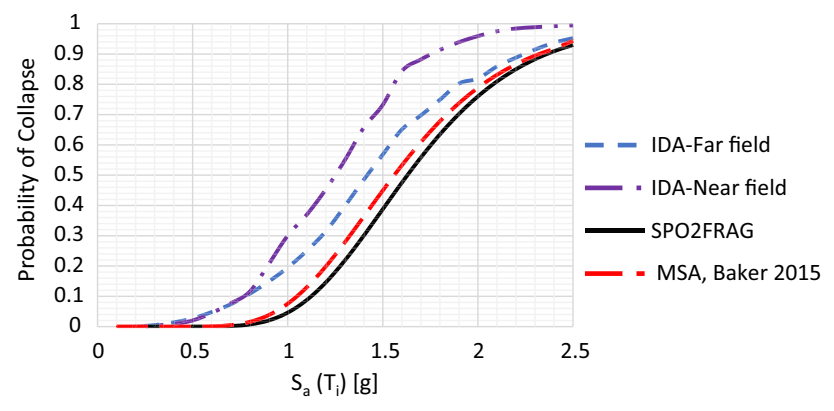

Fig. 14 Comparison of the SPO2FRAG Fragility Estimates and Other Fragility Curves (IDA and MSA)

selection method. All four curves have a similar S curve profile but both IDA curves are significantly more conservative than the MSA and SPO2FRAG results. The MSA method uses site-specific ground motions to generate the structural response and yields a fragility curve that is comparatively less conservative but potentially is a more realistic representation of the actual structural response of the given structure. The arguments in favor of this have been discussed in great detail in Baker's study (Baker, 2011). The SPO2FRAG fragility curve provides a similar result to the MSA fragility curve and usually falls within a 5\% confidence bound (see Table 7). Although MSA and SPO2FRAG show great similarity, the IDA results not only present a significant overall difference but a sensitivity to the motion type. The IDA-near field fragility curve is by far the most conservative of the four fragility curves. For a $S_{a}$ of $1 \mathrm{~g}$, the near field curve presents a $30 \%$ probability of collapse. In comparison, the far field records provide a probability of $19 \%$ which is a $11 \%$ lower probability. Compared against the MSA/SPO2FRAG, the probability of collapse drops to below $7 \%$ which is over a $23 \%$ lower probability. Notably the divergence between the near and far field results begins to appear around approximately $0.8 \mathrm{~g}$. This is comparable to what is also observed in the SPO2FRAG and MSA curves as they too begin to diverge at $0.8 \mathrm{~g}$, whether this is coincidence or if a deeper technical connection exists is something that can be explored in follow up studies. Later, we observe, at $\mathrm{S}_{\mathrm{a}}\left(\mathrm{T}_{\mathrm{i}}\right)=2 \mathrm{~g}$, the divergence between far field (81\%), MSA (78\%) and SPO2FRAG (76\%) is down to 5\%. The IDA near field takes a little bit longer to converge to comparable values of the other curves at $\mathrm{S}_{\mathrm{a}}\left(\mathrm{T}_{\mathrm{i}}\right)=2.5 \mathrm{~g}$.

\section{Conclusion}

In this study, the fragility curves of a three-story steel moment frame structure using three different analysis methods (IDA, MSA and SPO2FRAG) were investigated along with the effect of ground motions, their selection method and the curve fitting techniques.

To investigate, the effect of ground motion selection method on the predicted collapse fragility, two approaches for ground motion selection were examined. The first approach is to use a far field set and near field set of ground motions as the "dynamic loading" to the structure along with IDA to estimate the collapse capacity. This procedure does not require any prior information regarding structure location. The second approach is to use ground motions selected specifically for the site and ground motion amplitude of interest at fundamental period of the building (CMS), using the MSA approach. The third approach was SPO2FRAG in which analysis was performed using the Static Pushover Curve as an input to derive an equivalent SDOF system's backbone curve and then simulate, the nonlinear dynamic analysis by estimating $16 \%, 50 \%$ and $84 \%$ fractile IDAs.

Based on the collapse analysis of the case study structure, it was shown that collapse fragility of a structure varies significantly depending on the choice of ground motion selection method (refer Fig. 14). This is very apparent in the difference in the response data obtained via IDA near field and IDA far field ground motions. The IDA near field fragility curve is by far the most conservative of the four fragility curves. The significant increase in probability for near field motions is reasonable. These motions are characterized by higher displacements and accelerations due to the nature and magnitude of the motions. Considering only these types
Table 7 Median and Logarithmic Standard Deviation (Dispersion) for Fragility Curves

\begin{tabular}{lllll}
\hline Fragility Parameters & SPO2FRAG & MSA & IDA-Far Field & IDA-Near Field \\
\hline median $(\mathrm{g})$ & 1.629 & 1.56 & 1.4 & 1.24 \\
logarithmic standard deviation & 0.29 & 0.31 & 0.43 & 0.37 \\
\hline
\end{tabular}


of motions would then be highly conservative and can be seen as a worst-case scenario. On the other hand, the far field motions fall at the other side of the spectrum being less conservative for traditional IDA.

When looking at the MSA results, these now consider a different dynamic analysis method as well as the use of CMS for ground motion selection. These motions were also scaled differently from the IDA approach. The data shows that the MSA curve is far less conservative compared to both the IDA curves. This reaffirms previous researchers' results showing inherent conservatism with the IDA approach presenting MSA as being the more realistic representation of structural response. The SPO2FRAG fragility curve closely agrees with the MSA fragility curve within a 5\% confidence bound (see Table 7). Looking at the accuracy of the SPO2FRAG fragility curve (especially compared to both IDA curves), SPO2FRAG presents itself as a very viable approach due to the significant reduction in computation time (weeks to hours). This much shorter turnaround time to produce accurate fragility curves leads to a number of potential possibilities. For example, multiple structures that are in close proximity can be analyzed together quickly using SPO2FRAG to study the impact of seismic risk for a location as a whole. Also, if this kind of analysis can be performed on the buildings in a crowded downtown city block, this can yield new insights about the relationship between different buildings and how the seismic risk of one building can affect its immediate neighbors. These insights will help us better allocate our resources (i.e., time/capital/manpower) to the right structures when looking at broader efforts to make a region more resilient to seismic risk. SPO2FRAG analysis can be a quick and efficient approach to developing collapse fragility estimates for structures.

Fragility curves are an evolving area of study. Even with the use of traditional and new approaches, there is a band of similarity in collapse probability. However, it is the nuances in the results that must be considered in understanding how ground motion selection and fragility methods applied can lead to conservative results impacting our understanding of the potential risk in identifying seismic hazards.

Open Access This article is licensed under a Creative Commons Attribution 4.0 International License, which permits use, sharing, adaptation, distribution and reproduction in any medium or format, as long as you give appropriate credit to the original author(s) and the source, provide a link to the Creative Commons licence, and indicate if changes were made. The images or other third party material in this article are included in the article's Creative Commons licence, unless indicated otherwise in a credit line to the material. If material is not included in the article's Creative Commons licence and your intended use is not permitted by statutory regulation or exceeds the permitted use, you will need to obtain permission directly from the copyright holder. To view a copy of this licence, visit http://creativecommons.org/licenses/by/4.0/.

\section{References}

AISC 341 (2016). Seismic Provisions for Structural Steel Buildings. Chicago, IL.

Azarbakht, A., \& Dolsek, M. (2011). Progressive incremental dynamic analysis for first-mode dominated structures. Journal of Structural Engineering. https://doi.org/10.1061/(ASCE)ST.1943-541X. 0000282

Baker, J. W., \& Cornell, C. A. (2006). Spectral shape, epsilon and record selection. Earthquake Engineering \& Structural Dynamics, 35(9), 1077-1095.

Baker, J. W. (2011). Conditional mean spectrum: Tool for ground motion selection. Journal of Structural Engineering, 137(3), $322-331$.

Baker, J. W. (2013). Trade-offs in ground motion selection techniques for collapse assessment of structures. In: Proceedings Earthquake Engineering and Structural Dynamics, Vienna, Austria.

Baker, J. W. (2015). Efficient analytical fragility function fitting using dynamic structural analysis. Earthquake Spectra, 31(1), 579-599.

Baker, J. W., \& Lee, C. (2018). An improved algorithm for selecting ground motions to match a conditional spectrum. Journal of Earthquake Engineering, 22(4), 708-723.

Baltzopoulos, G., Barachino, R., Iervolino, I., \& Vamvatsikos, D. (2017). SPO2FRAG: Software for seismic fragility assessment based on static pushover. Bulletin of Earthquake Engineering, $15,4399-4425$.

Baharvand, A., \& Ranjbaran, A. (2020). A new method for developing seismic collapse fragility curves grounded on state-based philosophy. International Journal of Steel Structures, 20, 583-599.

Baharmast, H., Razmyan, S., \& Yazdani, A. (2015). Approximate incremental dynamic analysis using reduction of ground motion records. International Journal of Engineering, 28(2), 190-197.

Bazzurro, P., \& Cornell, C. A. (1999). Disaggregation of seismic hazard. Bulletin of the Seismological Society of America, 89(2), 501-520.

Brunesi, E., Nascimbene, R., Parisi, F., \& Augenti, N. (2015). Progressive collapse fragility of reinforced concrete framed structures through incremental dynamic analysis. Engineering Structures, 104, 65-79. https://doi.org/10.1016/j.engstruct.2015.09.024

Campbell, K. W., \& Bozorgnia, Y. (2008). NGA ground motion model for the geometric mean horizontal component of PGA, PGV, PGD and 5\% damped linear elastic response spectra for periods ranging from 0.01 to 10 s. Earthquake Spectra, 24(1), 139-171.

Christovasilis, I. P., Filiatrault, A., Constantinou, M. C., \& Wanitkorkul, A. (2008). Incremental dynamic analysis of woodframe buildings. Earthquake Engineering and Structural Dynamics, 38(4), 477-496. https://doi.org/10.1002/eqe.864

Cornell, C. A. (1968). Engineering seismic risk analysis. Bulletin of the Seismological Society of America, 58(5), 1583-1606.

Cornell, C. A., Jalayer, F., Hamburger, R. O., \& Foutch, D. A. (2002). Probability basis for 2000 SAC federal emergency management agency steel moment frame guidelines. Journal of Structural Engineering. https://doi.org/10.1061/(ASCE)0733-9445(2002) 128:4(526)

Fajfar, P. (2000). A nonlinear analysis method for performance based seismic design. Earthquake Spectra, 16(3), 573-592.

FEMA 356 (2000) Prestandard and Commentary for the Seismic Rehabilitation of Buildings. Washington DC.

Franchin, P., Petrini, F., \& Mollaioli, F. (2017). Improved risk-targeted performance-based seismic design of reinforced concrete frame structures. Earthquake Engineering and Structural Dynamics, 47(1), 49-67. https://doi.org/10.1002/eqe.2936

Gentile, R., Pampanin, S., Raffaele, D., \& Uva, G. (2019). Analytical seismic assessment of RC dual wall/frame systems using SLaMA: 
Proposal and validation. Engineering Structures, 188, 493-505. https://doi.org/10.1016/j.engstruct.2019.03.029

Han, S. W., \& Chopra, A. (2006). Approximate incremental dynamic analysis using the modal pushover analysis procedure. Earthquake Engineering and Structural Dynamics, 35(15), 1853-1873. https://doi.org/10.1002/eqe.605

Jalayer, F. (2003). Direct Probabilistic Seismic Analysis: Implementing Non-Linear Dynamic Assessments.

Jalayer, F., Beck, J. L., \& Zareian, F. (2012). Intensity measures of ground shaking based on information theory. ASCE J Eng Mech, 138(3), 307-316.

Jalayer, F., \& Cornell, C. A. (2008). Alternative non-linear demand estimation methods for probability-based seismic assessments. Earthquake Engineering and Structural Dynamics, 38(8), 951972. https://doi.org/10.1002/eqe.876

Jayaram, N., Lin, T., \& Baker, J. W. (2011). A computationally efficient ground-motion selection algorithm for matching a target response spectrum mean and variance. Earthquake Spectra, 27(3), 797-815.

Kramer, S. L. (1996). Geotechnical earthquake engineering. PrenticeHall International Series in Civil Engineering and Engineering Mechanics. Prentice Hall.

Krawinkler, H. Zareian, F. Lignos, D. G., \& Ibarra, L. F. (2009). Prediction of collapse of structures under earthquake excitations. In Proceedings COMPDYN 2009, ECCOMAS thematic conference on computational methods in structural dynamics and earthquake engineering, Greece: Rhodes, June 22-24.

McCallen, D., \& Larsen, S. (2003). NEVADA-A simulation environment for regional estimation of ground motion and structural response. Lawrence Livermore National Laboratory.

McGuire, R. K. (1995). Probabilistic seismic hazard analysis and design earthquakes: Closing the loop. Bulletin of the Seismological Society of America, 85(5), 1275-1284.

McGuire, R. K. (2004). Seismic hazard and risk analysis. Earthquake Engineering Research Institute.

McKenna, F., \& Fenves, G. L. (2000). Open system for earthquake engineering simulation (p. 2000). University of California.

Milosevic, J., Cattari, S., \& Bento, R. (2020). Definition of fragility curves through nonlinear static analyses: Procedure and application to a mixed masonry-RC building stock. Bulletin of Earthquake Engineering, 18, 513-545. https://doi.org/10.1007/ s10518-019-00694-1

Ni, P. P., Wang, S. H., Jiang, L., \& Huang, R. Q. (2012). Seismic risk assessment of structures using multiple stripe analysis. Applied Mechanics and Materials, 226-228, 897-900.

Pavel, F., Calotescu, I., Stanescu, D., et al. (2018). Life-cycle and seismic fragility assessment of code-conforming reinforced concrete and steel structures in Bucharest, Romania. International Journal of Disaster Risk Science, 9, 263-274. https://doi.org/10.1007/ s13753-018-0169-6
Petersen, M. D., A. D. Frankel, S. C. Harmsen, C. S. Mueller, K. M. Haller, R. L. Wheeler, R. L. Wesson, Y. Zeng, O. S, D. M. Perkins, N. Luco, E. H. Field, C. J. Wills, \& K. S. Rukstales (2008). Documentation for the 2008 update of the United States national seismic hazard maps: U.S. Geo- logical Survey Open-File Report 2008-1128. Technical Report.

Pitarka, A., Dalguer, L. A., Day, S. M., Somerville, P. G., \& Dan, K. (2009). Numerical study of ground-motion differences between buried-rupturing and surface-rupturing earthquakes. Bulletin of the Seismological Society of America, 99(3), 1521-1537. https:// doi.org/10.1785/0120080193

Pujari, N. N., Mandal, T. K., Ghosh, S., \& Lal, S. (2013). Optimisation of IDA-based fragility curves. In Safety, Reliability, Risk and Life-Cycle Performance of Structures \& Infrastructures (pp. 4435-4440).

PEER Ground Motion Database. https://ngawest2.berkeley.edu/

Ruggieri, S., Porco, F., \& Uva, G. (2020). A practical approach for estimating the floor deformability in existing RC buildings: Evaluation of the effects in the structural response and seismic fragility. Bulletin of Earthquake Engineering, 18, 2083-2113. https://doi. org/10.1007/s10518-019-00774-2

Saruddin, S. N. A., \& Nazri, F. M. (2015). Fragility Curves for Lowand Mid-rise Buildings in Malaysia. Procedia Engineering, 125, 873-878. https://doi.org/10.1016/j.proeng.2015.11.056

Scozzese, F., Tubaldi, E., \& Dall'Asta, A. . (2020). Assessment of the effectiveness of Multiple-Stripe Analysis by using a stochastic earthquake input model. Bulletin of Earthquake Engineering, 18, 3167-3203. https://doi.org/10.1007/s10518-020-00815-1

Silva, V., Akkar, S., Baker, J., et al. (2019). Current challenges and future trends in analytical fragility and vulnerability modeling. Earthquake Spectra, 35(4), 1927-1952. https://doi.org/10.1193/ 042418EQS1010

Somerville, P., Pitarka, A. (2006). Differences in Earthquake Source and Ground Motion Characteristics between Surface and Buried Crustal Earthquakes. In Proceedings of 8th US National conference on earthquake engineering.

Taiyari, F., Formisano, A., \& Mazzolani, F. M. (2019). Seismic behaviour assessment of steel moment resisting frames under nearfield earthquakes. International Journal of Steel Structures, 19, 1421-1430.

USGS Unified Hazard Tool. https://earthquake.usgs.gov/hazards/inter active/index.php.

Vamvatsikos, D., \& Cornell, C. A. (2001). Incremental dynamic analysis. Earthquake Engineering and Structural Dynamics, 31(3), 491-514.

Vielma, J. C., Porcu, M. C., \& López, N. (2020). Intensity measure based on a smooth inelastic peak period for a more effective incremental dynamic analysis. Applied Sciences, 10, 8632.

Publisher's Note Springer Nature remains neutral with regard to jurisdictional claims in published maps and institutional affiliations. 